\title{
The effects of small monetary incentive upon human lever pressing rates'
}

PAUL G. SWINGLE, MCGILL UNIVERSITY

DONALD MOORS, DALHOUSIE UNIVERSITY

Ss lever pressed on FR 5 for points which were, at times, redeemable for small amounts of money. Introduction of incentive retarded the lever pressing rates in fast responders but enhanced response rates in slow responders.

Several experimenters have reported results which suggest a brief decrease in response rate following reinforcement with human Ss (Helmstadter \& Ellis, 1952; Bruning, 1964; Ryan \& Moffitt, 1965; Swingle, Coady, \& Moors, 1966).

In the previous experiment (Swingle, Coady, \& Moors, 1966), a group of Ss who received only points having no monetary value was found to have considerably greater variability (i.e., fastest $S=9.4$ responses $/ \mathrm{sec}$; slowest $S=2.4 / \mathrm{sec}$ ) than a group monetarily rewarded for point accumulation (fastest $S=7.2 / \mathrm{sec}$; slowest $S$ $=4.2 / \mathrm{sec}$ ). From these results it was hypothesized that incentive beyond that necessary to maximize the S's response rate would actually retard the maximum rate. The present study was designed to test this notion in a within-subject design.

\section{METHOD}

\section{Subjects}

Ss for both experiments were male students registered in the introductory psychology course at Dalhousie University.

\section{Procedure}

Ss were seated in a ventilated cubicle about $5 \mathrm{ft}$ square, acoustically isolated from the laboratory equipment. The cubicle contained a standard 19 in. $x 21$ in. table model relay rack on which two lights, an electric impulse counter, and a Stromberg-Carlson cam key (No. 171D) were mounted.

The experimental session consisted of $60,10 \mathrm{sec}$ periods indicated by the onset of one of the two lights mounted on the S's panel, during which time the $S$ could accumulate points shown on his counter in a ratio of one point for every five lever presses (FR 5). The $10 \mathrm{sec}$ trial was timed from the S's first response, and the intertrial interval averaged $26 \mathrm{sec}$.

Tape recorded instructions informed all Ss that the study was concerned with "motor activity" and that they could accumulate points as shown on their counters if they pushed the lever rapidly whenever either one of their panel lights was illuminated, and that the faster they manipulated the lever the more points they would receive.

One of the two lights was labelled "Money Light" and Ss were informed that points accumulated during the time the Money Light was illuminated would be redeemed at one cent for every five points.
Ss were assigned to Fast responder and Slow responder groups on the basis of their baseline lever pressing rates under no reward (i.e., points having no monetary value). These groups represented the top and bottom thirds of each experimental sample, respectively.

\section{EXPERIMENT I}

Thirty male students were used in Experiment 1. Each $S$ responded for 20 trials for points only. The Money Light was illuminated during Trials 21 through 40, while during Trials 41-60 the points-only light was again illuminated.

Results

Ss were divided into top and bottom thirds on the basis of their Trial Block 4 (Trials 16-20) response rates. The obtained group of 10 Fast responders had a mean response rate of $\mathbf{7 . 7 2}$ responses/sec (fastest $S$ $=8.54 / \mathrm{sec}$ ), while the 10 Slow responders had a mean response rate of $6.62 / \mathrm{sec}$ (slowest $S=5.32 / \mathrm{sec}$ ). The difference between mean base rates for the Fast and Slow responses was reliable $(p<.01)$.

The results of the first experiment are shown in Fig. 1. The introduction of money trials results in a marked increase in the Slow group and very little in the Fast group. After 20 money trials the Fast group median responses/sec is almost identical to that of the last points-only trial block in Phase 1.

To determine whether there was greater suppression in the Fast group than in the Slow group, each S's performance in Phases 2 and 3 was compared against his own baseline performance (Trial Block 4). Phases 2 and 3 were divided into four five-trial blocks each and

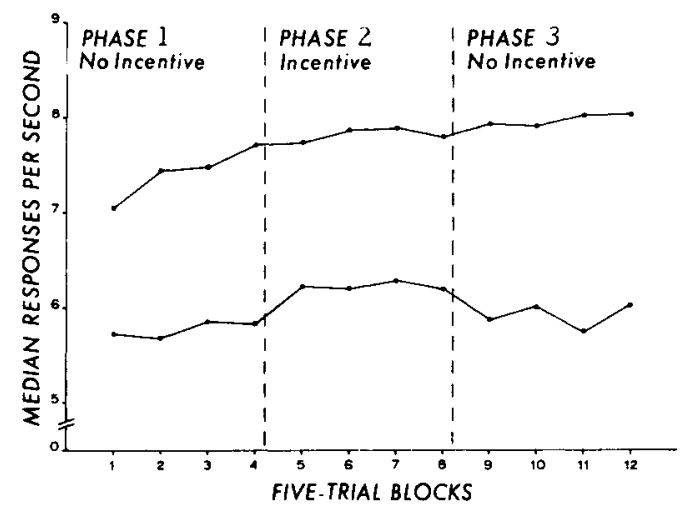

Fig. 1. Exp. 1. Median number of responses per second over 12 blocks of five trials per block for a group of Fast responders (top curve) and Slow responders (bottom curve) as a function of the presence or absence of monetary incentive. 
Ss were scored on a 0 through 4 basis in each phase, depending upon the number of five-trial blocks with a response rate below baseline. Thus, a Swhose response rate dropped below baseline on three of the four trial blocks in Phase 2 and one out of four in Phase 3 received a score of 3 and 1 for Phases 2 and 3, respectively. The data from the Fast and Slow groups were submitted to an analysis of variance. The group by phase interaction was significant $(F=4.67$, $\mathrm{df}=$ $1 / 18, p<.05)$. The mean suppression score during Phase 2 was 1.7 for the Fast group and .9 for the Slow group, while in Phase 3 the mean suppression score was .9 for the Fast group and 1.8 for the Slow group.

The total suppression score for each group over the course of Phases 2 and 3 is shown in Fig. 2. The curves show quite clearly that greater suppression of response rate occurs in the Fast group when incentive is introduced, while the Slow group's rate drops with the removal of the monetary incentive.

\section{EXPERIMENT 2}

The second experiment explored the effects of small incentive introduced only during early performance. Fifteen male students were used, and divided into Fast and Slow responders on the basis of their performance during Trial Block 4. During the first 20 trials, the Money Light was illuminated and points were again valued at $1 / 5$ cent each.

Results

The results, shown in Fig. 3, seem quite clear. When the incentive is removed the Slow responding group's rate drops off rapidly, while the Fast responders' rates tend to increase. The suppression score was calculated for each group (i.e., number of five-trial rates

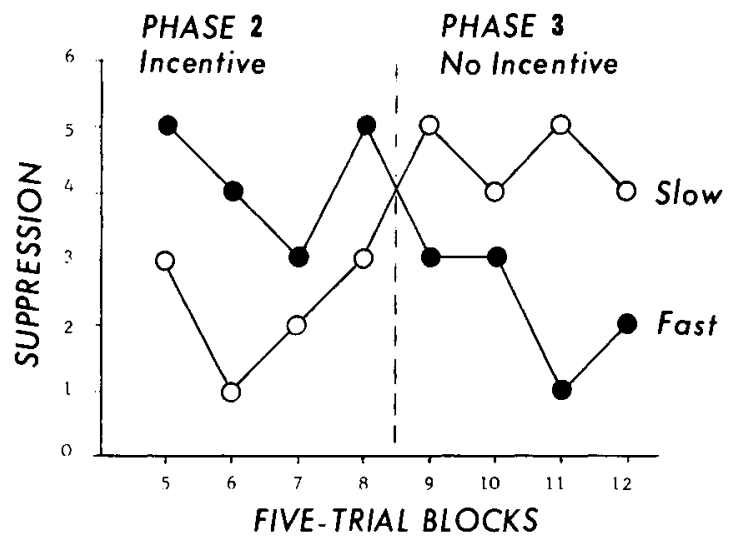

Fig. 2. Exp. 1. Total suppression score (number of 5-trial blocks with response rate below baseline) for the Fast and Slow responder groups during Phase 2 (Trial Blocks 5-8) and Phase 3 (Trial Blocks 9-12).

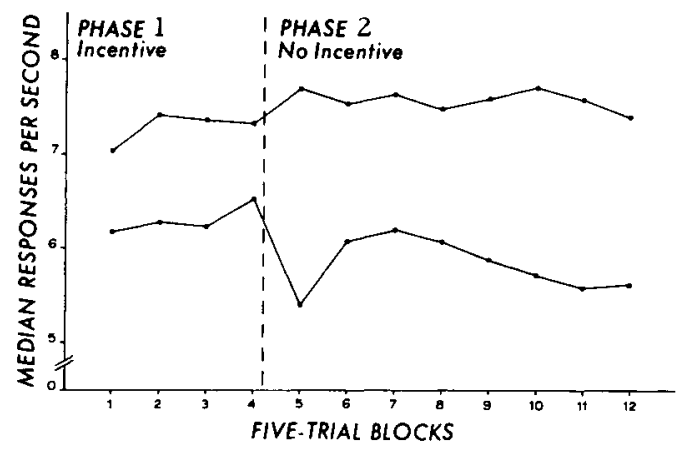

Fig. 3. Exp. 2. Median number of responses per second over 12 blocks of five trials per block for a group of Fast responders (top curve) and Slow responders (bottom curve) as a function of the presence or absence of monetary incentive.

during Blocks 5 to 12 which were lower than the Trial Block 4 base rate). In the Slow group more than $87 \%$ of the nonrewarded five-trial blocks fell below baseline whereas less than $8 \%$ did so in the Fast group. This difference in suppression scores was found to be significant by the Mann-Whitney $U$. statistic $(p<.01)$.

\section{DISCUSSION}

The results of the present studies indicate that incentive may retard the acquisition of maximum performance in Fast responders. The previous study (Swingle, Coady, \& Moors, 1966) demonstrated that prolonged added incentive results in slower average rates for Fast responders than when Fast responders lever press for no incentive other than performance feedback. The present experiments indicate that the addition of small monetary incentive retards the acquisition of optimal performance levels in Fast responders, whereas the removal of added incentive results in sudden decreases in Slow responders' lever pressing rates.

\section{References}

BRUNING, J. L. The effects of magnitude of reward and percentage of reinforcement on a lever movement response. Child Develpm., 1964, $35,281-286$.

HELMSTADTER, G. C., \& ELLIS, D. S. Rate of manipulative learning as a function of goal-setting techniques. J. exp. Psychol., 1952, 43, 125-129.

RYAN, T. J., \& MOFFITT, A. R. Response speed as a function of age incentive value, and reinforcement schedule. Child Develpm., 1966, 37, 103-113.

SWINGLE, P. G., COADY, H., \& MOORS, D. The effects of performance feedback, social and monetary incentive upon human lever pressing rate. Psychon. Sci, 1966, 4, 209-210.

Note

1. This research was supported by a grant from the Department of National Health and Welfare of Canada to the first author. 